\title{
A Frequency Domain Design Method For Sampled-Data Compensators
}

\section{Niemann, Hans Henrik; Jannerup, Ole Erik}

\section{Published in:}

American Control Conference

Publication date:

1990

Document Version

Publisher's PDF, also known as Version of record

Link back to DTU Orbit

Citation (APA):

Niemann, H. H., \& Jannerup, O. E. (1990). A Frequency Domain Design Method For Sampled-Data Compensators. In American Control Conference (pp. 1156-1158). IEEE.

\section{General rights}

Copyright and moral rights for the publications made accessible in the public portal are retained by the authors and/or other copyright owners and it is a condition of accessing publications that users recognise and abide by the legal requirements associated with these rights.

- Users may download and print one copy of any publication from the public portal for the purpose of private study or research.

- You may not further distribute the material or use it for any profit-making activity or commercial gain

- You may freely distribute the URL identifying the publication in the public portal

If you believe that this document breaches copyright please contact us providing details, and we will remove access to the work immediately and investigate your claim. 
Hans Henrik Niemann and ole Jannexup

Control Engineering Institute

Technical University of Dennark

Building 424,DK-2800 Lyngby, Denmark

Abstract.

A new approach to the design of a sampled-data compensator in the frequency domain is investigated.

The starting point is a continuous-time compensator for the continuous-time system which satisfy specific design criteria. The new design method will graphically show how the discrete-time compensator and the sampling period should be selected so the sampled-data feedback system approximate the continuous-time feedback systen as good as possible.

\subsection{Introduction.}

Design of sampled-data compensators isn't straightforward, which be due to the combination of discrete-time and continuous-time elements. However, a large number of design methods for digital control systens have been developed in the last 20-30 years, see f.ex. [1-6]. Most of these design nethods are discrete-time methods which have been used directly, or after sowe nodifications, for the sampled-data compensator design.

The other way is to design the sampled-data compensators by using continuous-tine methods followed by a discretization. The advantages by using this design schene are: $A$ model of the plant doesn't need to be discretized and continuous-tine design methods can be used. Continuous-time nethods have in general better properties than the equvialently discrete-time methods, f.ex. IQG design. The difficults of this design scheme is that of developing a sampled-data compensator such that the closed loop properties are achieved as close as possible in the sampled-data feedback system. This step isn't straightforward, but there exist several methods which can be used for this discretization with pre-warped Tustin's nethod as one of the better methods [7]. However, in spite of good discretization methods, the resulting sampled-data feedback systen will in general be inferior to the continuous-time feedback system in terms of robustness margins. The reason is the introduction of extra phase-lag at crossover frequencies from the prefilter $F(s)$ and a hold $H(s)$ introduced by the sampled-data controller.

In this paper we will derive a discretization method which will minimize the effect from $F(s)$ and $H(s)$ in the closed loop systen. The method consist of Tustin's discretization method combined by conic sector theory. The method has been studied in $[7,8]$.

The paper is organized as follows. In sec. 2 previous results from $[7,8]$ are shortly sumarized. In sec. 3 the new approach for sampled-data compensator design based on the previous results will be given followed by an example in sec. 4.

2.0 Previous results.

Consider the continuous-time and the sanpled-data feedback system in fig. la and $1 \mathrm{~b}$.

The sampled-data compensator in the dashed box is represented by the LTV-operator $\mathrm{K}$. $B$ is a LTV-operator on account of the sampler.

By using conic sectors it is possible to approximate the LTV-operator $\mathbf{K}$ with $a$ UTI-operator and an approximation error, $[7,8]$.

Let $B$ be placed inside a cone:

$K \subset \operatorname{Cone}(C, R)$

where $c$ is the cone center which can be regarder as an approxination of $\mathrm{K}$. $\mathrm{R}$ is the cone radius and it can be treated as the approximation error. Normally $\&$ and $R$ will be LTI-operators and can therefore be represented by their Laplace transforns.

In [7] it has been proved that the optimal ITI choice for the cone center $C(s)$ is:

$C(s)=\frac{1}{T} H(s) D(z) F(s)$

For this choice of the center it is also 
possible to give an analytical expression for the cone radius, but it isn't needed here.

By using the cone center in eq. (2) as a LTI approximation of the sampled-data compensator, it is simple to see that our design problem can now be formulated as [8].

Determine $D(z)$ such that:

$\min _{D(z)}\left\|\frac{1}{T} H(s) D\left(e^{s T}\right) F(s)-K(s)\right\|_{\tau}, \tau>0$

However, there doesn't exist any analytical methods for this optimization in eq. (3). One way to do the optimization is to augment $K(s)$ with a lead-compensator before the continuous-time compensator is discretized. Tustin's discretization method can be used with advantage which will be demonstrated in sec. 4.

Before $D(z)$ is computed from the lead-compensated continuous-time compensator $K_{1}(s)$, a reduced order model of $K_{1}(s)$ is normally computed, so that the order of $D(z)$ is equal to the order of $\mathbf{R}(\mathrm{s})$.

Different lead-compensators can be used with advantage as $f . e x$.

$L(s)=\frac{(s / a+1)^{k}}{(s / b+1)^{k}}$

with $b$ equal to the half sample frequency $\pi / T$, a is a free design parameter and $k$ is normal selected as the difference between numbers of poles and zeros in $\mathrm{H}(\mathrm{s}) \mathrm{F}(\mathrm{s})$. In [8] the step responce has been used to optimize the a parameter in $I(s)$. However, it is also possible to do the optimization in the frequency-domain, which will be done in the next section.

3.0 Graphically design.

Here we wouldn't use eq. (3) directly for the optimization of $D(z)$, because it is difficult to evaluate how a difference between $\mathrm{K}(\mathrm{s})$ and $\frac{1}{T} H(s) D(z) F(s)$ will affect the properties of the closed-10op system. In the MIMO case the compensator can be skewed which will complicate the comparison further. These problems can be reduced if we look at closed-loop transfer functions instead. Here the sensitivity transfer function $S(j \omega)$ will be used. The sensitivity functions $S$ are given by:

$S_{c}(j \omega)=(I+K(J \omega) G(J \omega))^{-1}$

$S_{d}(j \omega)=\left(I+\frac{1}{T} H(j \omega) D\left(e^{j \omega T}\right) F(j \omega) G(j \omega)\right)^{-1}$

The optimization problem can now be defined as:
$\Delta S_{i}(j \omega)=\min _{D(z)} \sigma_{i}\left(S_{d}(j \omega)\right)-\sigma_{i}\left(S_{c}(j \omega)\right)$

$i=\min , \max$

where the $i$ 'th singular value $\sigma_{i}(\cdot)$ is used as the norm.

It is now easy to plot $\Delta S$ as function of $\omega$ for different lead-compensators or parameters in the lead-compensator. Normally the sanple perion $T$ is also a variable in the design of the sampled-data compensator and $\Delta S$-curves for different sample periods must also be plotted. By doing this, it could be difficult to evaluate the $\Delta S$-curves for different lead-compensators at different sample periods. One way to make the connection between different sample periods, lead-compensators and the $\Delta S$-curves more clear is by changing eq. (6) to:

$d S_{i}\left(\omega_{0}\right)=\min _{D(z)}\left(\sigma_{i}\left(S_{\alpha}\left(j \omega_{0}\right)\right)-\sigma_{i}\left(S_{c}\left(j \omega_{0}\right)\right)\right)(7)$

where $\omega_{0}$ is a special frequency where we want to evaluate the sensitivity function. The frequency $\omega_{0}$ can f.ex. be the frequency for which $S_{\mathrm{c}}(j \omega)$ is maximal, if such a frequency exist, else a frequency close to the closed-loop cross-over will normally be a reasonble choice.

The change of eq. (6) to eq. (7) has made it possible to plot $d S_{i}\left(\omega_{0}\right)$ as function of the sample period $T$ instead of $\omega$. This will normally result in linears curves for $d S_{i}\left(\omega_{0}\right)$ as function of $T$ for different lead-compensators in a log-log, see section 4, when Tustin's discretization method is used, see [9], but a proof is not known.

It is now very simple to select that lead-compensator, from the diagram, which will give the smallest increase of the sensitivity curve. The sample period $T$ can also be selected from the diagram by using e.g. conditions on a maximal descrease of the nominel performance, i.e. increase of the sensitivity curve. However, the selection of the sample period is normally a compromise between different conditions as e.g. a minimal sample period for a reasonble implementation of the sampled-data compensator and maximal increase of the sensitivity curve.

Based on the linear curves for $d S_{i}\left(w_{0}\right)$ it is now possible to outline a scheme for design of sampled-data compensators from continuous-time compensators.

I Select a lead-compensator

II Create $K_{l}(s)=K(s) L(s)$

III Make a reduced order compensator $K_{r}(s)$ from $K_{l}(s)$ if it is necessary 
IV Compute $D(z)$ for different sample periods $T$ usnig Tustin's method on $K_{r}(s)$

$v$ Compute the $d S_{i}\left(\omega_{0}\right)$-curves by changing parameters in the lead-compensator.

VI Select the paraneters for the lead-compensator $I(s)$ and the sample period from the $d S_{i}\left(\omega_{0}\right)$ curves.

The design scheme will be demonstrated on a sIso system in next section.

1.0 Erample.

A continuous-tine feedback system has the following plant and compensator [8]:

$G(s)=\frac{150}{(s+1)(s+3)}$

$K(s)=\frac{(s+3)^{2}}{(s+.4)(s+22.5)}$

The sampled-data compensator is now designed by using the method outlined in this paper.

The prefilter and holds are chosen to be:

$F(s)=\frac{\omega_{f}}{s^{2}+1.4 \omega_{f} s+\omega_{f}^{2}}$

$H(s)=\frac{1+e^{-s 7}}{s}$

In this example $\omega_{t}$ is chosen as $1 / 4$ of the sample frequency.

The lead-compensator given by eq. (4) is used with $a=35$ and $k=2$. The results are shown in fig. $2-4$. The $d S_{\max }\left(\omega_{0}\right)$ -curves are shown in fig. 2 for $\omega_{0}=10$ $\mathrm{rad} / \mathrm{sec}$. in the case without using a lead-compensator (dS1) and when the lead-compensator in eq. (4) is used (dS2). The sensitivity curves are shown in fig. 3 and 4 for the dS1 and ds2-curves. The lower curve in fig. 3 and 4 is the original continuous-tine feedback system. The other curves are computed for $T=.5 T_{0}$, $T_{0}, 1.25 T_{0}$ and $1.5 T_{0}$ with $T_{0}=\pi / 100$. The advantage by using lead-compensation in design of sanpled-data compensators turns out very clear in this example. Other examples are given in (9).

References.

[1] G.F. Franklin and J.D. Powell, 1980

[2] E.I. Jury, 1958

[3] G.F. Franklin and J.R. Ragazzini, 1958

[4] R. Isernann, 1981

[5] J. Ackermann, 1985

[6] P.S. Maybeck, 1982

[7] P.M. Thompson, 1982, Ph.D thesis

[8] P.H. Thompson et.al., 1986 ACC-86

[9] H.H. Niemann, 1988, Ph.D thesis

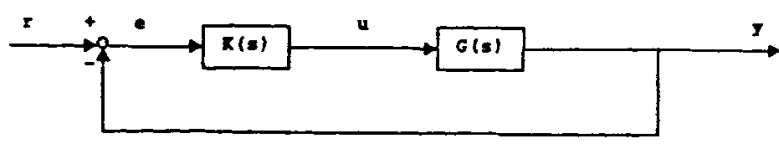

Pig. Ia The continuoun-time teedback systed.

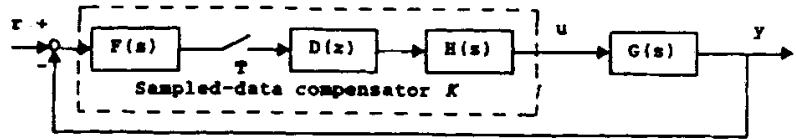

Fig. ib the sanpled-date feudbeck systos.
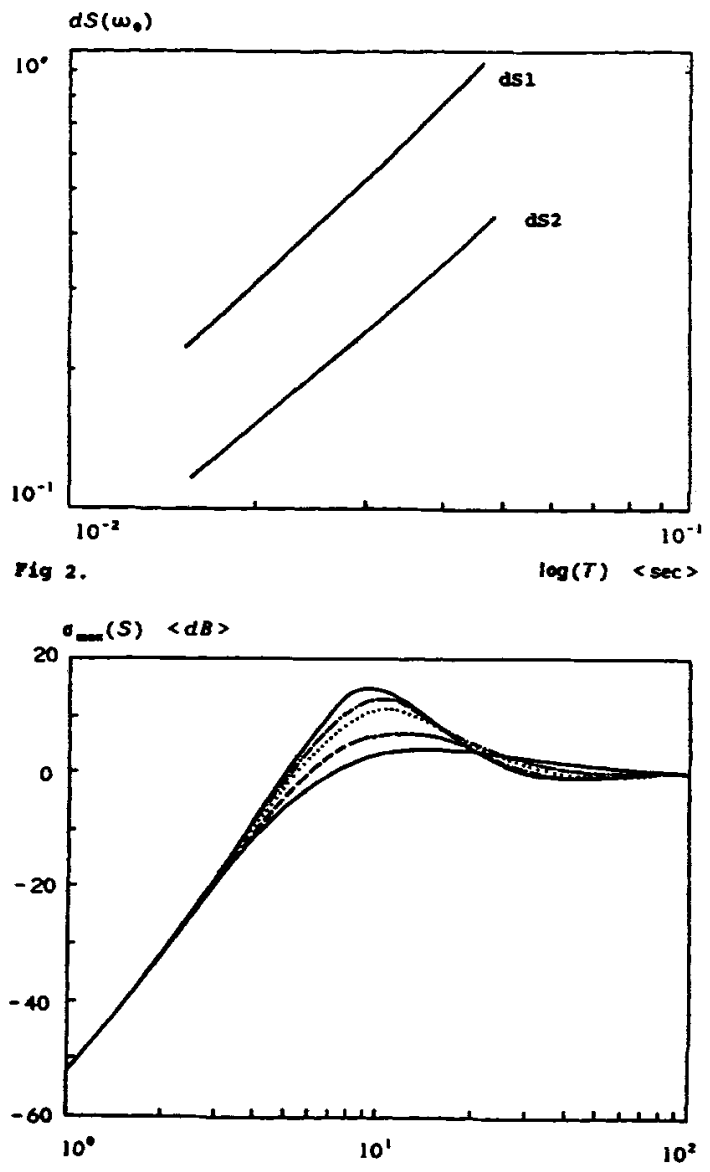

Fig. 3.

$\log (\omega)<\mathrm{rad} / \mathrm{sec}>$

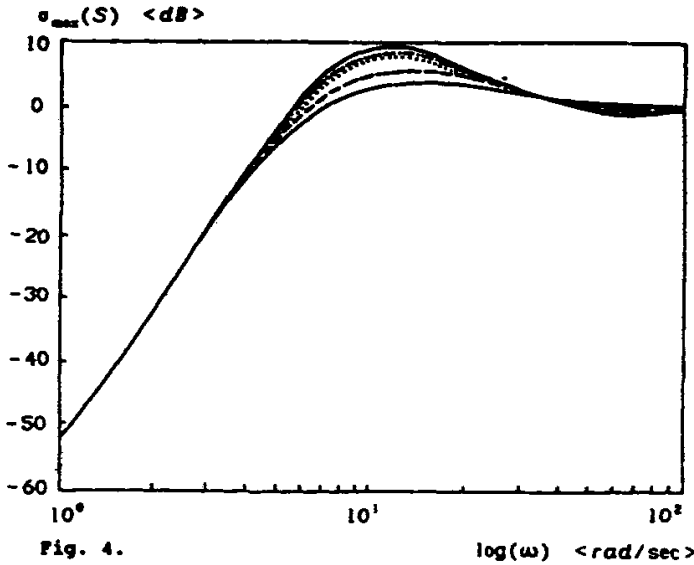

